ORIGINAL ARTICLE

\title{
Occupational and environmental exposures and lung cancer in an industrialised area in Italy
}

\author{
V Fano, P Michelozzi, C Ancona, A Capon, F Forastiere, C A Perucci
}

Occup Environ Med 2004;61:757-763. doi: 10.1136/oem.2003.010728

See end of article for authors' affiliations .......................

Correspondence to: Dr V Fano, Department of Epidemiology ASL/RME,

$\checkmark$ ia di Santa Costanza 53 00198 Rome, Italy; fano@asplazio.it

Accepted 25 March 2004

\begin{abstract}
Aims: To investigate the effects of occupational exposures and residence near to industrial sites on lung cancer mortality in an area in Italy.

Methods: 234 cases of lung cancer and 729 controls matched by sex, age, and date of death were enrolled. Environmental exposure was evaluated using historical residence data. A geographical information system was used to compute distances from residence to pollution source (cement factory, power plants, harbour) and an average distance was computed for each subject. Odds ratios (OR) and $95 \%$ confidence intervals (Cl) in a logistic regression model were used to estimate the relative risk of lung cancer associated with the risk factors (smoking habits and occupational exposure) collected by questionnaire; ORs for distances from pollution sources and from city centre were computed, adjusting for smoking habits, education, and occupation.

Results: Smoking habits ( $\leqslant 10$ cigarettes/day, $O R=2.28 ; 11-20, O R=4.64 ;>20, O R=6.61)$ and occupational exposure to asbestos $(O R=3.50)$ were significantly associated with lung cancer risk. Reported traffic level of area of residence and residence near the four sources were not associated with increased risk of lung cancer. There was a significantly increased risk for those residing outside the city centre, in the southern outskirts $(O R=1.51)$.

Conclusions: The increased lung cancer risk observed in the area can partly be explained by occupational exposures. The increased risk in the outskirts of the city is consistent with the results of dispersion models that indicate high levels of pollutant deposition in the same area.
\end{abstract}

$\mathrm{T}$ he area of Civitavecchia, an industrial town located north of Rome (Lazio region, Italy), has been an object of concern because of several sources of environmental contamination potentially affecting the residential communities: a harbour, a cement factory, and several power plants are present in the area. The mortality analysis of residents showed a $20-30 \%$ increase in lung cancer compared with regional data since the 1980s. As a result of public concern and media reports, the regional government requested epidemiological studies on the workers employed in the industrial settings and on the nearby population. The excess mortality for lung cancer in the general population observed in Civitavecchia may be attributable to smoking or to occupational exposures, but the possibility that the increased risk arises from environmental factors also needs to be assessed.

Tobacco smoke is the leading cause in lung cancer death, but other causes may contribute to increased risk, including indoor and outdoor environmental exposures, occupational exposures, and diet. ${ }^{1}$ Several occupations have been associated with a known or suspected excess risk of lung cancer. ${ }^{2}$ In a study published in 1981 Doll and Peto estimated that about $15 \%$ of lung cancers in men and $5 \%$ in women could be attributable to workplace exposures in the USA; these figures have been confirmed recently in a review of occupational studies conducted in western Europe. ${ }^{4}$

Three occupational studies have been carried out recently in the area of Civitavecchia. A cohort study among workers employed in one of the thermoelectric power plants showed an excess of lung cancer deaths among those with a duration of exposure longer than 10 years. ${ }^{5}$ Lung cancer deaths were significantly higher in a cohort of seamen with at least one sailing (standardised mortality ratio $($ SMR $)=1.71) .{ }^{6}$ Finally, a study among dockyard workers in the harbour showed an excess of lung cancer $($ SMR $=2.27){ }^{7}$
The evidence implicating air pollution as a risk factor in the aetiology of lung cancer has been reviewed..$^{8-12}$ An association between lung cancer risk and residence in urban areas ${ }^{13-15}$ and in areas with emissions from certain industries has been reported. ${ }^{16}{ }^{17}$ Three cohort studies conducted in the USA during the 1990s showed a relation between several indicators of air pollution levels and cancer risk among residents. ${ }^{18-20}$ Dockery et al, in the Six-City Study, compared the most versus the least polluted cities ${ }^{18}$ and found that fine particulate matter $\left(\mathrm{PM}_{10}\right)$ was associated with lung cancer mortality $\left(15-20 \%\right.$ increase in risk per $\left.10 \mu \mathrm{g} / \mathrm{m}^{3}\right)$. A study conducted on approximately 500000 adult men followed from 1982 to $1998^{19}$ indicated a significantly increased mortality risk ratio for lung cancer (relative risk $(\mathrm{RR})=1.14,95 \%$ confidence interval $(\mathrm{CI})=1.04$ to 1.23 ) for a difference of $10 \mu \mathrm{g} / \mathrm{m}^{3}$ of $\mathrm{PM}_{2.5}$. A study carried out among 6338 California Seventh Day Adventists, who were currently non-smokers, ${ }^{20}$ reported that lung cancer incidence was associated with the annual mean level of $\mathrm{PM}_{10}$, with an estimated risk of 5.21 (1.94 to 13.99) comparing the highest with the lowest pollutant levels. More recently, a cohort study conducted in Norway, with a 27 year follow up of 16209 men aged 40 to 49 years from Oslo, found that the adjusted risk ratio for developing lung cancer was 1.08 (1.02 to 1.15 ) for a $10 \mu \mathrm{g} / \mathrm{m}^{3}$ increase in average home address nitrogen oxide exposure between 1974 and 1978. ${ }^{21}$ A casecontrol study conducted in an industrialised town of northern Italy showed an increased risk for lung cancer among residents in the most polluted city areas compared with people living in less polluted areas (odds ratio $(\mathrm{OR})=1.5(1.0$

Abbreviations: IARC, International Agency for Research on Cancer; ISCO, International Standard Classification of Occupation; ISIC, International Standard Industrial Classification of all Economic Activities; SMR, standardised mortality ratio 


\section{Main messages}

- The increased lung cancer risk observed among residents in industrial areas may reflect the overall role of several factors: confounding by smoking, occupational exposure to agents associated with lung cancer, and exposure to air pollution.

- Results from this case-control study indicate that the increased risk for lung cancer observed in an Italian area can partially be explained by tobacco smoke and occupational exposures.

- Geographical analysis did not show a clear increase in risk of lung cancer with distance from the pollution sources.

- An increased risk of lung cancer observed in the suburban area is consistent with the results of dispersion models that indicate a high deposition of pollutants in the same area.

to 2.2 ) for residents in the city centre; $\mathrm{OR}=1.4$ ( 1.0 to 2.1 ) for residents in the industrial area). ${ }^{22}$

Our aim in the present case-control study was to investigate the effects of occupational and environmental exposures on lung cancer in Civitavecchia.

\section{METHODS}

\section{Study area}

The area of Civitavecchia lies along the northern cost of Rome and has about 51000 inhabitants $^{23}$ (year 2001; 1991 census data; $49 \%$ male; population density of 712 inhabitants per $\left.\mathrm{km}^{2}\right)$. In the city area there is a large harbour $\left(241000 \mathrm{~m}^{2}\right)$ mainly used for ferry traffic, but merchant ships and tankers also anchor there (fig 1). Environmental surveys indicate that dusty materials (around 500000 tons a year) are the main source of pollution from the harbour, causing increased dust dispersion in the air while they are transferred from buckets to trucks. Another source of pollution from the harbour is the traffic of heavy vehicles and ferries; ships and ferries use a large amount of fuel containing high sulphur levels (2.9\%),

\section{Policy implications}

- Public health concerns about the effects of industrial emissions are high.

- Epidemiological monitoring is a key component in assessing the impact of industrial emissions.

and producing substantial quantities of sulphur oxides and particulates.

Three thermoelectric power plants are located in the study area: Fiumaretta, Tor Valdaliga North, and Tor Valdaliga South. The Fiumaretta power plant is located in the northern part of the periphery but has not been active since 1990. Its activity began in 1953 as a coal fired plant producing of 70 MW of power; later the fuel was changed to oil and in 1969 the power was increased to $460 \mathrm{MW}$. The power plant Tor Valdaliga South is located about $4 \mathrm{~km}$ north west of the built up area. It was expanded since 1964 and produces $1140 \mathrm{MW}$ of power. The power plant Tor Valdaliga North is located about $5 \mathrm{~km}$ north west of the built up area, near Tor Valdaliga South; it has been active since 1984 and produces $2640 \mathrm{MW}$ of power. Measurement of the emissions from the power plants showed the presence of particles, nitrogen dioxide $\left(\mathrm{NO}_{2}\right)$, and sulphur dioxide $\left(\mathrm{SO}_{2}\right)$. Emission dispersion models, described in a study conducted by the National Electrical-Energy Industry (ENEL), show that the maximum concentration of pollutants emitted from the power plant Tor Valdaliga South was located at $7 \mathrm{~km}$ southeast of the source. A large cement factory $\left(6500 \mathrm{~m}^{2}\right)$ has been active since the beginning of the century and is now inside the town of Civitavecchia.

Historical data for $\mathrm{SO}_{2}, \mathrm{NO}_{2}$, and total suspended particle (TSP) levels collected by the local health unit since the 1980s show high values which decreased during the early 1990s. Pollutant values, however, fell within the range of air quality standards defined by the World Health Organisation (WHO), ${ }^{24}$ except for increased values of $\mathrm{SO}_{2}$ observed in the period 1992-94 in two monitoring stations located about 6 $\mathrm{km}$ east of the city centre. During the period 1989-91 the Italian National Agency for New Technologies, Energy and

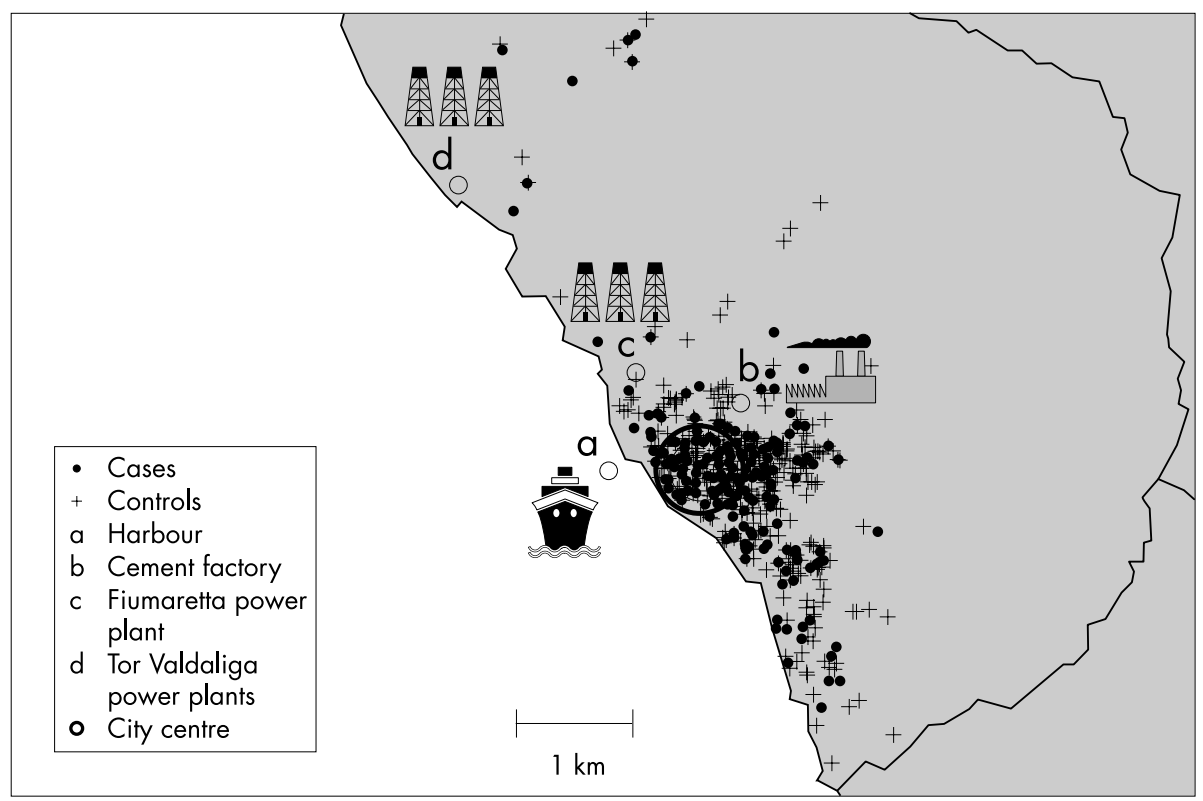

Figure 1 Area of Civitavecchia: localisation of the air pollution sources and distribution of residences of cases and controls. 
the Environment (ENEA) conducted a survey on the chemical composition of the particulate matter. The survey highlighted relatively high levels of lead, vanadium, and polycyclic aromatic hydrocarbons (PAH). In addition, in several sampling sites cadmium, copper, and zinc were detected. However, air concentrations of these substances were below WHO air quality guideline values and were consistent with other findings reported for urban areas.

\section{Study population}

The source for cases and controls was the regional mortality registry (ReNCaM). Cases were male and female residents in the municipality of Civitavecchia who died during the period between l January 1987 to 31 December 1995 with a diagnosis of lung cancer (code $=162$, according to the ninth revision of the International Classification of Diseases (ICDIX)). Preliminary calculations on study power suggested the random selection of three controls for each case eligible for the study. Each control was matched to the corresponding case by sex, age (plus or minus two years), and date of death (plus or minus six months). Controls were not eligible if they had died from respiratory diseases (ICD-IX code, 460-519), or from "other or ill-defined cancer of respiratory tract" (ICD-IX code, 165). Cases and controls were excluded from the analysis if they had lived in the municipality of Civitavecchia for less than five years.

\section{Demographic variables, smoking habits, and occupational exposure}

For each subject, two next of kin were traced from the registry office of the municipality of Civitavecchia. One of these close relatives was then interviewed by a trained interviewer, giving priority in the following order: husband/ spouse, son/daughter, other less close relatives. A structured questionnaire was used to collect demographic data, lifetime smoking habits, detailed work history, and residential history. Traffic level was assessed through perceived frequency of buses or lorries near residence of maximum length (never/rarely, few times per day, many times per day). Socioeconomic status was estimated through educational level-that is, the highest grade of education completed by the subject. Information on smoking habits included the following: whether the subject did or did not smoke; whether the subject smoked cigarettes and/or cigars and/or pipe; the year of cessation, where the subject had been an active smoker who quit smoking; for cigarette smokers, the average number of cigarettes smoked daily; passive smoking exposure.

Occupational history was assessed, inquiring about all occupations held, starting from the most recent. Subjects were classified as being exposed to occupations or industries known (list A) or suspected (list B) to be associated with lung cancer. ${ }^{25}$ The lists were translated into the codes used in the International Standard Classification of Occupation (ISCO $)^{26}$ and the International Standard Industrial Classification of all Economic Activities (ISIC 71). ${ }^{27}$ Exposure to occupations at risk was also assessed by filling in a check list of 23 occupations considered to increase the risk for lung cancer according to the International Agency for Research on Cancer (IARC). ${ }^{2}$

\section{Environmental exposure}

Residence history in Civitavecchia for the 30 year period preceding death was individually assessed through the registry office. Geographical coordinates of residences were measured using a global positioning system (Garmin GPS III plus). For subjects changing residency during the study period, all residences were considered and all coordinates measured. The geographical locations of the three power plants, the harbour, and the cement factory were identified in the same way. A geographical information system was used to compute distances between each residence and each source. To take into account the change in distance from the sources, a weighted average distance was computed for each subject to yield an average distance from each source of exposure. The duration periods of residences were used as weights. An average latitude was computed for each subject using the same method in order to classify their residences as belonging to the city centre $(\leqslant 1 \mathrm{~km}$ radius) or to the outskirts $(>1 \mathrm{~km}$ north or $>1 \mathrm{~km}$ south of the city centre). The analysis was restricted to a time window of 5-15 years before death, on the assumption that this window corresponds to the relevant induction and latency period for lung cancer. ${ }^{19}$ The distances from the sources were classified using concentric circles to define three areas at increasing distance: $<0.7 \mathrm{~km}, 0.7-1.3 \mathrm{~km}$, and $>1.3 \mathrm{~km}$ from the harbour; $<0.6$ $\mathrm{km}, 0.6-1.2 \mathrm{~km}$, and $>1.2 \mathrm{~km}$ from the cement factory; $<1 \mathrm{~km}, \mathrm{l}-2 \mathrm{~km}$, and $>2 \mathrm{~km}$ from Fiumaretta power plant; and $<4 \mathrm{~km}, 4-6 \mathrm{~km}$, and $>6 \mathrm{~km}$ from the Tor Valdaliga power plants (considered as a single point source).

\section{Statistical analyses}

An unconditional logistic regression model was used to estimate the odds ratios and the $95 \%$ confidence intervals for lung cancer associated with each of the individual characteristics collected by the questionnaire, adjusted for sex, age, year of death, education, smoking habits (number of cigarettes/day), and number of occupations at risk (none $v$ one or more). An interaction between sex and age significantly increased the fit of the model. The unconditional logistic regression model was used as an alternative to the conditional approach as both yielded similar results. Odds ratios for area of residence were computed, comparing individuals living in the outskirts of Civitavecchia (north and south) with those living inside the circle of $1 \mathrm{~km}$ radius from the city centre. Adjusted odds ratios for exposure to single occupations increasing the risk for lung cancer were computed, but this analysis was restricted to men owing to the small numbers available for women. Adjusted odds ratios for weighted distance from the four sources were also computed. The statistical package STATA was used for all analyses. ${ }^{28}$

\section{RESULTS}

In all, 266 cases and 798 controls were enrolled in the study; one case and three controls were excluded because during the 5-15 year period before death they were not resident in the study area for a minimum of five years. For 31 cases and 66 controls it was not possible to administer the questionnaire (because no next of kin could be traced or because they refused to be interviewed). The final number of subjects included in the analysis was 963 (234 cases and 729 controls).

Table 1 shows the distribution of lung cancer cases and controls for sex, age, and the other variables collected in the questionnaire, along with the adjusted odds ratios and 95\% confidence intervals. Higher education levels (high school, university degree) were associated with an increased lung cancer risk, although not significantly so. A significantly increased risk of lung cancer was associated with smoking habits in all dose categories $(<10$ cigarettes/day, $\mathrm{OR}=$ $2.28 ; 11-20$ cigarettes/day, $\mathrm{OR}=4.64 ;>20$ cigarettes/day, $\mathrm{OR}=6.61$; test for trend: $\mathrm{p}<0.001$ ). Adjusted odds ratios for exposure to occupation "known" or "suspected" to be at risk for lung cancer were 1.30 and 0.82 , respectively. Occupational history of exposure to substances at risk, according to the IARC classification, was associated with an increased lung cancer risk $(\mathrm{OR}=1.49$ for two or more 
Table 1 Characteristics of lung cancer cases and controls in Civitavecchia: frequency distribution, adjusted odds ratios (OR), and $95 \%$ confidence intervals (CI)

\begin{tabular}{|c|c|c|c|c|c|c|}
\hline \multirow[b]{2}{*}{ Variable } & \multicolumn{2}{|c|}{ Cases $(n=234)$} & \multicolumn{2}{|c|}{ Controls ( $n=729$ ) } & \multirow[b]{2}{*}{$\mathrm{OR}^{*}$} & \multirow[b]{2}{*}{$95 \% \mathrm{Cl}$} \\
\hline & n & $\%$ & n & $\%$ & & \\
\hline \multicolumn{7}{|l|}{ Sex } \\
\hline Male & 201 & 85.9 & 626 & 85.9 & & \\
\hline Female & 33 & 14.1 & 103 & 14.1 & & \\
\hline \multicolumn{7}{|l|}{ Age (years) } \\
\hline$<60$ & 46 & 19.7 & 138 & 18.9 & & \\
\hline 60 to 69 & 92 & 39.3 & 263 & 36.1 & & \\
\hline 70 to 74 & 33 & 14.1 & 125 & 17.2 & & \\
\hline $75+$ & 63 & 26.9 & 203 & 27.8 & & \\
\hline \multicolumn{7}{|l|}{ Educationt, $\ddagger$} \\
\hline None & 35 & 15.0 & 137 & 18.8 & 1.00 & - \\
\hline Primary & 108 & 46.1 & 331 & 45.4 & 1.30 & 0.83 to 2.04 \\
\hline Middle school & 39 & 16.7 & 142 & 19.5 & 1.11 & 0.64 to 1.91 \\
\hline High school & 25 & 10.7 & 62 & 8.5 & 1.60 & 0.85 to 3.00 \\
\hline University & 8 & 3.4 & 22 & 3.0 & 1.67 & 0.65 to 4.24 \\
\hline Other & 6 & 2.5 & 16 & 2.2 & 1.39 & 0.48 to 4.03 \\
\hline Missing & 13 & 5.6 & 19 & 2.6 & & \\
\hline \multicolumn{7}{|c|}{ Smoking habits (cigarettes/day) $\ddagger, \S$} \\
\hline None & 31 & 13.3 & 201 & 27.6 & 1.00 & - \\
\hline$\leqslant 10$ & 18 & 7.7 & 97 & 13.3 & 2.28 & 1.08 to 4.80 \\
\hline $11-20$ & 72 & 30.7 & 199 & 27.3 & 4.64 & 2.48 to 8.69 \\
\hline$>20$ & 106 & 45.3 & 219 & 30.0 & 6.61 & 3.52 to 12.42 \\
\hline Missing & 7 & 3.0 & 13 & & & \\
\hline \multicolumn{7}{|l|}{ Occupational historyt $\S$. } \\
\hline Never exposed & 179 & 76.5 & 565 & 77.5 & 1.00 & - \\
\hline Ever list $B /$ never list $A$ & 29 & 12.4 & 106 & 14.5 & 0.82 & 0.51 to 1.32 \\
\hline Ever exposed list A & 26 & 11.1 & 58 & 8.0 & 1.30 & 0.77 to 2.19 \\
\hline \multicolumn{7}{|c|}{ No. of occupations at riskt, $\S^{, * *}$} \\
\hline None & 89 & 38.1 & 321 & 44.0 & 1.00 & - \\
\hline 1 & 71 & 30.3 & 226 & 31.0 & 1.22 & 0.80 to 1.85 \\
\hline$\geqslant 2$ & 74 & 31.6 & 182 & 25.0 & 1.49 & 0.97 to 2.31 \\
\hline \multicolumn{7}{|c|}{ Length of residence (years) $+, \ddagger, \S$} \\
\hline$\leqslant 30$ & 83 & 35.5 & 227 & 31.1 & 1.00 & - \\
\hline$>30$ & 151 & 64.5 & 502 & 68.9 & 0.81 & 0.58 to 1.14 \\
\hline \multicolumn{7}{|c|}{ Reported traffic level†, $‡, \S, † \dagger$} \\
\hline Low & 147 & 62.8 & 419 & 57.5 & 1.00 & - \\
\hline Medium & 28 & 12.0 & 93 & 12.7 & 0.86 & 0.53 to 1.39 \\
\hline High & 59 & 25.2 & 215 & 29.5 & 0.82 & 0.57 to 1.78 \\
\hline Missing & 0 & & 2 & 0.3 & & \\
\hline \multicolumn{7}{|l|}{ Area of residencet, $\neq, \S$} \\
\hline City centre & 136 & 58.4 & 477 & 65.4 & 1.00 & \\
\hline Northern outskirts & 35 & 15.0 & 99 & 13.6 & 1.29 & 0.82 to 2.03 \\
\hline Southern outskirts & 62 & 26.6 & 153 & 21.0 & 1.51 & 1.04 to 2.18 \\
\hline \multicolumn{7}{|c|}{$\begin{array}{l}\text { *Oddds ratios adjusted for sex, age, year of death, and interaction between sex and age. } \\
\text { †Additionally adjusted for smoking habits. } \\
\text { †Additionally adjusted for number of risk occupations. } \\
\text { \$Additionally adjusted for education. } \\
\text { 'List B, occupations suspected to increase risk of lung cancer; List A, occupations known to increase risk of lung } \\
\text { cancer. } \\
{ }^{* *} \text { Exposure to occupation considered to increase risk of lung cancer according to the International Agency for } \\
\text { Research on Cancer (IARC) classification. } \\
\text { ††Traffic level was estimated through reported frequency of buses or lorries near residence of maximum length } \\
\text { (low, never/rarely; medium, a few times a day; many times a day). }\end{array}$} \\
\hline
\end{tabular}

exposures). A significantly increased risk was observed for those residing in the southern outskirts of the city (southern outskirts $v$ city centre: $\mathrm{OR}=1.51$ ). Increased risks were not observed for the other variables (length of residence, reported traffic level).

Table 2 shows the distribution among male cases and controls of occupational exposures increasing the risk for lung cancer, and the estimated odds ratios after adjusting for age, year of death, and smoking habits. Subjects can be classified in more than one occupational category. Asbestos workers showed a significantly increased risk of lung cancer
$(\mathrm{OR}=3.45)$. An excess of risk, although not statistically significant, was also observed for asphalt workers $(\mathrm{OR}=$ 1.66), welders $(\mathrm{OR}=1.55)$, leather workers $(\mathrm{OR}=1.42)$, foundrymen $(\mathrm{OR}=2.00)$, butchers $(\mathrm{OR}=1.64)$, and seamen $(\mathrm{OR}=1.53)$.

Figure 1 reports the location of the pollution sources and shows the residences distribution of cases and controls. Estimated odds ratios for each distance from the four sources are given in table 3 . The distances were computed as averages from all residences held during the study period. Residence near the four sources was not associated with an increased 


\begin{tabular}{|c|c|c|c|c|c|c|c|}
\hline \multirow[b]{2}{*}{ Exposure* } & & \multicolumn{2}{|c|}{ Cases $(n=201)$} & \multicolumn{2}{|c|}{ Controls $(n=626$ ) } & \multirow[b]{2}{*}{ ORt } & \multirow[b]{2}{*}{$95 \% \mathrm{Cl}$} \\
\hline & & 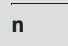 & $\%$ & $\bar{n}$ & $\%$ & & \\
\hline \multirow{2}{*}{ Asphalt } & No & 176 & 91.7 & 583 & 95.4 & 1.00 & - \\
\hline & Yes & 16 & 8.3 & 28 & 4.6 & 1.66 & 0.86 to 3.20 \\
\hline \multirow{2}{*}{ Coal } & No & 195 & 98.5 & 594 & 95.7 & 1.00 & - \\
\hline & Yes & 3 & 1.5 & 27 & 4.4 & 0.30 & 0.09 to 1.03 \\
\hline \multirow{2}{*}{ Paint } & No & 173 & 87.4 & 540 & 89.1 & 1.00 & - \\
\hline & Yes & 25 & 12.6 & 66 & 10.9 & 1.05 & 0.63 to 1.74 \\
\hline \multirow{2}{*}{ Asbestos } & No & 167 & 90.8 & 583 & 97.2 & 1.00 & - \\
\hline & Yes & 17 & 9.2 & 17 & 2.8 & 3.45 & 1.68 to 7.07 \\
\hline \multirow{2}{*}{ Welder } & No & 176 & 89.3 & 574 & 93.0 & 1.00 & - \\
\hline & Yes & 21 & 10.7 & 43 & 7.0 & 1.55 & 0.88 to 2.72 \\
\hline \multirow{2}{*}{ Construction } & No & 160 & 82.1 & 483 & 78.5 & 1.00 & - \\
\hline & Yes & 35 & 18.0 & 132 & 21.5 & 0.70 & 0.46 to 1.07 \\
\hline \multirow[t]{2}{*}{ Truck driver } & No & 185 & 92.5 & 565 & 90.7 & 1.00 & - \\
\hline & Yes & 15 & 7.5 & 58 & 9.3 & 0.76 & 0.41 to 1.39 \\
\hline \multirow{2}{*}{ Garage/filling station } & No & 197 & 98.5 & 602 & 96.3 & 1.00 & - \\
\hline & Yes & 3 & 1.5 & 23 & 3.7 & 0.34 & 0.10 to 1.15 \\
\hline \multirow{2}{*}{ Leather } & No & 196 & 98.5 & 617 & 98.7 & 1.00 & - \\
\hline & Yes & 3 & 1.5 & 8 & 1.3 & 1.42 & 0.34 to 5.86 \\
\hline \multirow{2}{*}{ Foundry } & No & 192 & 97.5 & 616 & 98.6 & 1.00 & - \\
\hline & Yes & 5 & 2.5 & 9 & 1.4 & 2.00 & 0.63 to 6.35 \\
\hline \multirow{2}{*}{ Butcher } & No & 194 & 97.0 & 614 & 98.2 & 1.00 & - \\
\hline & Yes & 6 & 3.0 & 11 & 1.8 & 1.64 & 0.57 to 4.71 \\
\hline \multirow{2}{*}{ Seaman } & No & 160 & 80.4 & 548 & 87.8 & 1.00 & - \\
\hline & Yes & 39 & 19.6 & 76 & 12.2 & 1.53 & 0.99 to 2.38 \\
\hline \multirow{2}{*}{ Longshoreman } & No & 160 & 80.8 & 524 & 84.1 & 1.00 & - \\
\hline & Yes & 38 & 19.2 & 99 & 15.9 & 1.14 & 0.74 to 1.75 \\
\hline \multirow{2}{*}{ Cement } & No & 186 & 94.4 & 581 & 93.6 & 1.00 & - \\
\hline & Yes & 11 & 5.6 & 40 & 6.4 & 0.82 & 0.40 to 1.67 \\
\hline \multirow{2}{*}{ Power plant } & No & 173 & 86.9 & 555 & 89.2 & 1.00 & - \\
\hline & Yes & 26 & 13.1 & 67 & 10.8 & 1.10 & 0.66 to 1.82 \\
\hline \multicolumn{8}{|c|}{$\begin{array}{l}\text { *Exposure to risk occupations was assessed by filling in a check list of } 23 \text { occupations considered to increase th } \\
\text { risk for lung cancer according to the International Agency for Research on Cancer (IARC). }{ }^{2} \\
\text { †Odds ratios (exposed } v \text { non-exposed) adjusted for age, year of death, and smoking habits (number of cigarette } \\
\text { per day). }\end{array}$} \\
\hline
\end{tabular}

risk for lung cancer. A significantly greater risk of lung cancer was observed among people living furthest from the cement factory $(>1.2 \mathrm{~km} v<0.6 \mathrm{~km}$ : OR $=1.81)$. No differences in risk were found for cases living in areas at the various distances from the harbour and from the thermoelectric power plants.

Table 3 Lung cancer risk in concentric areas at different distances from the industrial sources: frequency distribution of cases and controls, adjusted odds ratios (OR) and $95 \%$ confidence intervals (CI)

\begin{tabular}{|c|c|c|c|c|c|c|}
\hline \multirow{2}{*}{$\begin{array}{l}\text { Distance from source } \\
(\mathrm{km})\end{array}$} & \multicolumn{2}{|c|}{ Cases $(n=234)$} & \multicolumn{2}{|c|}{ Controls $(n=729$ ) } & \multicolumn{2}{|l|}{ All } \\
\hline & n & $\%$ & n & $\%$ & $\mathrm{OR}^{*}$ & $95 \% \mathrm{Cl}$ \\
\hline \multicolumn{7}{|l|}{ Harbour } \\
\hline$<0.7$ & 85 & 36.3 & 282 & 38.7 & 1.00 & \\
\hline 0.7 to 1.3 & 79 & 33.8 & 249 & 34.2 & 1.12 & 0.77 to 1.61 \\
\hline$>1.3$ & 70 & 29.9 & 198 & 27.1 & 1.31 & 0.86 to 1.86 \\
\hline \multicolumn{7}{|l|}{ Cement factory } \\
\hline$<0.6$ & 29 & 12.4 & 142 & 19.5 & 1.00 & \\
\hline 0.6 to 1.2 & 93 & 39.7 & 282 & 38.7 & 1.61 & 0.99 to 2.62 \\
\hline$>1.2$ & 112 & 47.9 & 305 & 41.8 & 1.81 & 1.13 to 2.92 \\
\hline \multicolumn{7}{|l|}{ Fiumaretta power plant } \\
\hline$<1$ & 11 & 4.7 & 44 & 6.0 & 1.00 & \\
\hline 1 to 2 & 115 & 49.1 & 399 & 54.7 & 1.18 & 0.58 to 2.44 \\
\hline$>2$ & 112 & 46.2 & 286 & 39.3 & 1.60 & 0.78 to 3.29 \\
\hline \multicolumn{7}{|c|}{ Tor Valdaliga power plants } \\
\hline$<4$ & 12 & 5.1 & 22 & 3.0 & 1.00 & \\
\hline 4 to 6 & 170 & 72.7 & 582 & 79.8 & 0.56 & 0.26 to 1.21 \\
\hline$>6$ & 52 & 22.2 & 125 & 17.2 & 0.85 & 0.38 to 1.92 \\
\hline
\end{tabular}

*Odds ratios adjusted for sex, age, year of death, smoking habits, education level, and exposure to occupations increasing risk for lung cancer according to the International Agency for Research on Cancer (IARC) ${ }^{2}$. 


\section{DISCUSSION}

We investigated the role of reported occupational history and environmental exposures in lung cancer mortality among residents in an industrial town in Italy. The results of the study clearly indicate that exposure in several occupations entails an increased risk of lung cancer. The interpretation of the geographical analysis is not straightforward because no excesses were found in the traffic area or near the industrial plants, but an increased risk was found in the southern suburban area, away from the pollution sources.

Results from emission dispersion models may provide useful hints for evaluating the results, although they are available only for one thermoelectric plant. It is clear that for the thermoelectric plants the concentration of soil pollutants is related to chimney height and to both the intensity and duration of prevailing winds. For the Tor Valdaliga South power station, model results indicate that the area located at $7 \mathrm{~km}$ from the point emission was the area with the maximum concentration of pollutants, outside the Civitavecchia municipal boundary. It is likely that contamination from other sources (including the old Fiumaretta power plant or the more recent Torre Valdaliga North, with shorter and taller chimneys than Torre Valdaliga South, respectively) would also be present in the same area. The area of high contamination is close to the southern part, where the excess of lung cancer was found.

In this study, the distance of residences from the five points was highly correlated and we are aware that reciprocal confounding is likely to have occurred. On the other hand, it was not possible to build up an integrated index of industrial exposure owing to the geographical location of the sources, as the cement factory and the harbour are located near the city centre and both power plants are placed outside the town. As the distance increases from the first two sources, it simultaneously decreases from the power plants, at least for those living in the northern part of the area. We are aware that there are several difficulties in establishing a causal link between the environmental exposures from all the investigated sources and lung cancer in this area. The conclusion from our analysis is only suggestive, and, as any post hoc interpretation, it has several weaknesses. On the other hand, controversial evidence of a positive role of residence near an industrial source of air pollution has also been reported in other studies..$^{29}{ }^{30}$ In our study the increased lung cancer risk observed in the outskirts of the city may be attributable to socioeconomic differences ${ }^{31-33}$ or to other environmental exposures that our study did not take into considerationfor example, radon ${ }^{34}$ - or to immigration into the study area of people with lower lung cancer risk. ${ }^{35}$ However, our data were adjusted for education, a proxy for socioeconomic status. Furthermore, when the risk of mortality was evaluated taking into account the length of residence in Civitavecchia (more than 30 years $v$ less) no differences in cancer risk were observed between the two groups.

Difficulties in assessing environmental exposure and its long term effects have posed numerous methodological problems in epidemiological studies, mainly concerning the use of aggregated data for exposure and confounders. The advantage of this study design is the availability of individual data on known risk factors for lung cancer, such as smoking habits and occupational exposure, which can be controlled as confounders while focusing on environmental exposures. In our study the source for the selection of controls was the registry of residents. The response rate was $88 \%$ for cases and $93 \%$ for controls. Differential bias in evaluating the distance from air pollution sources between cases and controls is not likely to have occurred, as ascertainment of residential history was independent of case-control status. Women were included in the geographical analysis, although the number of cases was small and the percentage of non-respondents to the questionnaire was higher for women than for men, owing to the difficulty in finding a next of kin with women's longer life expectancy. Information on occupational history and smoking habits were obtained from next of kin, mostly spouses or offspring; employment history and smoking habits may therefore be incomplete or inaccurate, leading to misclassification of these variables. Although a gradient of lung cancer risk with respect to total cigarette consumption was observed, this was less steep than in other case-control studies. The lower odds ratios for smokers might be explained by the fact that this was a mortality study; therefore controls may include smoking related causes of death.

Finally, it should be stressed that we found an increased risk for lung cancer among asbestos workers as well as among seamen, welders, and foundry workers. These results, though not statistically significant in our study, confirm the carcinogenic role of occupational exposures that are classified by the IARC as increasing the risk of lung cancer, ${ }^{2}$ and they are consistent with other previous reports. ${ }^{63-39}$ Our findings also indicate that a fraction of the increased lung cancer risk in the area is attributable to occupational exposure, even after adjusting for smoking habit. The overall results regarding occupation, however, are likely to be conservative, as nondifferential bias may have occurred because of the use of next of kin as a source of information. ${ }^{40}{ }^{41}$

In conclusion, the increased lung cancer risk observed in the area of Civitavecchia can partly be explained by occupational exposures. Results from the geographical analysis did not point to a clear role of the proximity to the industrial sites considered. The increased risk observed in the outskirts of the city is consistent with the results of dispersion models indicating high level of pollutants deposition in the same area.

\section{ACKNOWLEDGEMENTS}

We wish to thank Michela Mari and Daniela Collepiccoli for their contribution to data collection and the reviewers for their helpful comments. We also wish to thank Margaret Becker for her editorial help.

\section{Authors' affiliations}

V Fano, P Michelozzi, C Ancona, F Forastiere, C A Perucci, Department of Epidemiology, Roma E Health Authority, Rome, Italy

A Capon, Agency for Public Health, Lazio Region, Italy

\section{REFERENCES}

1 Alberg AJ, Samet JM. Epidemiology of lung cancer. Chest 2003;123(1 suppl):21-49S.

2 IARC. International Agency for Research on Cancer. IARC monographs on the evaluation of the carcinogenic risk of chemicals to humans overall evaluation of carcinogenicity: an updating of IARC monographs volumes 1 to 42. Lyon: IARC, 1987.

3 Doll R, Peto R. The causes of cancer: quantitative estimates of avoidable risk of cancer in the united states today. New York: Oxford University Press, 1981.

4 Boffetta P, Kogevinas M. Introduction: Epidemiologic research and prevention of occupational cancer in Europe. Environ Health Perspect 1999;107/suppl 2):229-231.

5 Forastiere F, Pupp N, Magliola E, et al. Respiratory cancer mortality among workers employed in thermoelectric power plants. Scand J Work Environ Health 1989; 15:383-6.

6 Rapiti E, Turi E, Forastiere F, et al. A mortality cohort study of seamen in Italy. Am J Ind Med 1992;21:863-72.

7 Bonassi S, Ceppi M, Puntoni R, et al. Mortality studies of dockyard workers (longshoremen) in Italy. Am J Ind Med 1985;7:219-27.

8 Pershagen G. Air pollution and cancer. IARC Sci Publ 1990;104:240-51.

9 Cohen AJ, Pope CA. Lung cancer and air pollution. Environ Health Perspect 1995; 103(suppl 8):219-24.

10 Katsouyanni K, Pershagen G. Ambient air pollution exposure and cancer. Cancer Causes Control 1997;8:284-91.

11 Lagorio S, Forastiere F, Lipsett M, et al. Air pollution from traffic and the risk of tumors. Ann Ist Super Sanita 2000;36:311-29.

12 Cohen AJ. Outdoor air pollution and lung cancer. Environ Health Perspect 2000;108(suppl 4):743-50. 
13 Nyberg F, Gustavsson P, Järup L, et al. Urban air pollution and lung cancer in Stockholm. Epidemiology 2000;1 1:487-95.

14 Pershagen G, Simonato L. Epidemiological evidence for the carcinogenity of air pollutants. Air pollution and human cancer. In: Tomatis L, ed. European School of Oncology monograph. Berlin: Springer-Verlag, 1990.

15 Vena JE. Air pollution as a risk factor in lung cancer. Am J Epidemiol 1982; 1 16:42-56.

16 Jedrychowski W, Becher $\mathrm{H}$, Wahrendorf J, et al. A case-control study of lung cancer with special reference to the effect of air pollution in Poland. J Epidemiol Community Health 1990;44:114-20.

17 Pless-Mulloli T, Phillimore P, Moffatt S, et al. Lung cancer, proximity to industry, and poverty in northeast England. Environ Health Perspec 1998; 106:189-96.

18 Dockery DW, Pope CA, Xu X, et al. An association between air pollution and mortality in six US cities. N Engl J Med 1993;329:1753-9.

19 Pope CA, Burnett RT, Thun MJ, et al. Lung cancer, cardiopulmonary mortality, and long-term exposure to fine particulate air pollution. JAMA 2002;287: 1132-41.

20 Beeson WL, Abbey DE, Knutsen SF. Long-term concentrations of ambient air pollutants and incident lung cancer in California adults: results from the AHSMOG study. Environ Health Perspec 1998;106:813-23.

21 Nafstad P, Haheim LL, Oftedal B, et al. Lung cancer and air pollution: a 27 year follow up of 16209 Norwegian men. Thorax 2003;58:1071-6.

22 Barbone $F$, Bovenzi M, Cavallieri $F$, et al. Air pollution and lung cancer in Trieste, Italy. Am J Epidemiol 1995;141:1 161-9.

23 National Institute of Statistics 2003. (http://demo.istat.it).

24 World Health Organisation. Air quality guidelines for Europe. Copenhagen: WHO Regional Publications, European Series No 23, 1987.

25 Ahrens W, Merletti F. A standard tool for the analysis of occupational lung cancer in epidemiologic studies. Int J Occup Environ Health 1998 OctDec; $4: 236-40$.

26 International Labour Office (ILO). International standard classification of occupations, 2nd ed. Geneva: International Labour Office Publications, 1968.

27 United Nation Publications. International standard industrial classification of all economic activities (ISIC). New York: United Nations Publishing Service, 1971.
28 Stata Statistical Software - Release 6.0. College Station, Texas: Stata Corporation, 1999

29 Polednak AP, Janerich DT. Lung cancer in relation to residence in census tracts with toxic waste disposal sites: a case-control study in Niagara County, New York. Environ Res 1989;48:29-41.

30 Marsh GM, Stone RA, Esmen NA, et al. A case-control study of lung cancer mortality in four rural Arizona smelter towns. Arch Environ Health 1998;53:15-28.

31 Van Loon AJ, Brug J, Goldbohm RA, et al. Differences in cancer incidence and mortality among socio-economic groups. Scand J Soc Med 1995;23:110-20.

32 Van Loon AJ, Goldbohm RA, limert K, et al. Socioeconomic status and lung cancer incidence in men in The Netherlands: is there a role for occupational exposure? J Epidemiol Community Health 1997;51:24-9

33 Mao $Y$, Hu J, Ugnat AM, et al. Socioeconomic status and lung cancer risk in Canada. Int J Epidemiol 2001;30:809-17.

34 Lubin JH, Boice JD. Lung cancer risk from residential radon: meta-analysis of eight epidemiologic studies. J Natl Cancer Inst 1997;89:49-57.

35 Tenkanen L. Migration to towns, occupation, smoking, and lung cancer: experience from the Finnish-Norwegian lung cancer study. Cancer Causes Control 1993;4:133-41.

36 Jöckel KH, Ahrens W, Wichmann HE, et al. Occupational and environmental hazards associated with lung cancer. Int J Epidemiol 1992;21:202-13.

37 Pohlabeln H, Boffetta P, Ahrens W, et al. Occupational risks for lung cancer among non-smokers. Epidemiology 2000;11:532-8.

38 Jöckel KH, Ahrens W, Jahn I, et al. Occupational risk factors for lung cancer: a case-control study in West Germany. Int J Epidemiol 1998;27:549-60.

39 Steenland K, Boffetta P. Lead and cancer in humans: where are we now? Am J Ind Med 2000;38:295-9.

40 Lyon JL, Egger MJ, et al. Misclassification of exposure in a case-control study: the effects of different types of exposure and different proxy respondents in a study of pancreatic cancer. Epidemiology 1992;3:223-31.

41 Gladen B, Rogan WJ. Misclassification and the design of environmental studies. Am J Epidemiol 1979;109:607-16.

\section{Making Health Care Safer 2004}

21-22 October 2004

Royal College of Physicians, London

A two day conference for all professionals dedicated to providing safer health care for all.

Register now! Early booking discount available.

See website for details: www.quality.bmipg.com 